\title{
BREVE DISCUSSÃO SOBRE A HISTÓRIA DA INCLUSÃO NO BRASIL À LUZ DA COMPLEXIDADE
}

\author{
Maria Dolores Fortes Alves \\ Universidade Federal de Alagoas - UFAL (Brasil) \\ mdfortes@gmail.com · https://orcid.org/0000-0002-2292-8518 \\ Adalberto Duarte Pereira Filho \\ Universidade Federal de Alagoas - UFAL (Brasil) \\ adalberto-duarte@hotmail.com ·https://orcid.org/0000-0001-5583-6305 \\ Tamires Leite \\ Universidade Federal de Alagoas - UFAL (Brasil) \\ ttamireslleite@gmail.com · http://orcid.org/0000-0002-3880-4560
}

\begin{abstract}
Resumo. A inclusão postula pelo direito de todos os sujeitos serem aceitos e respeitados diante das diferenças, com igualdade de condições perante a sociedade. A inclusão na contemporaneidade ainda é um elemento inquietador e de produção de temor na prática educativa. Não é apenas o professor que fica tomado pela inabilidade na lide com sujeitos com deficiência na escola. Podemos dizer que a grande maioria dos atores educativos comungam dessa inquietude. O presente trabalho aborda a história da inclusão no Brasil e propõe, a partir do paradigma da Complexidade, um fazer ecoformador. De modo específico, esse estudo teve por objetivos realizar um recorte teórico-bibliográfico acerca da inclusão e da ecoformação; delinear o fenômeno da inclusão a partir de um panorama histórico; e discutir a inclusão ecossistêmica. Trata-se de uma pesquisa de natureza qualitativa, do tipo webgráfica. A partir da base de dados online Scielo, foram buscados estudos que enfocassem o tema da inclusão a partir do paradigma da Complexidade. Para essa busca, foram utilizados os seguintes termos: "inclusão", "formação de professores" e "ecoformação". O material recuperado foi sistematizado e, a partir das lentes da teoria da Complexidade, foi possível evidenciar. Partindo da análise histórica do processo de inclusão no Brasil, constatamos que torna-se imperativo para o professor romper com práticas pedagógicas clássicas em favor do desenvolvimento de sujeitos peculiares, singulares.
\end{abstract}

Palavras-chave: Inclusão, Ecoformação, Formação de professores.

\section{BRIEF DISCUSSION ON THE HISTORY OF INCLUSION IN BRAZIL IN THE LIGHT OF COMPLEXITY}

\begin{abstract}
Inclusion postulates the right of all subjects to be accepted and respected in the face of differences, with equal conditions before society. Inclusion in contemporaneity is still a disturbing element and a source of fear in educational practice. It is not only the teacher who is taken by the inability to deal with subjects with disabilities in school. We can say that the vast majority of educational actors share this concern. The present work addresses the history of inclusion in Brazil and proposes, based on the paradigm of Complexity, an eco-educational approach. Specifically, this study aimed to make a theoreticalbibliographic cut about inclusion and eco-training; to delineate the phenomenon of inclusion from a historical perspective; and to discuss the ecosystem inclusion. It is a qualitative research of a web-based nature. From the online database Scielo, studies were sought that focused on the theme of inclusion from the paradigm of Complexity. For this search, the following terms were used: "inclusion", "teacher training" and "eco-training". The recovered material was systematized and, from the lenses of the theory of complexity, it was possible to evidence. Based on the historical analysis of the inclusion process in Brazil,
\end{abstract}


we found that it is imperative for the teacher to break with classical pedagogical practices in favor of the development of unique, peculiar subjects.

Keywords: Inclusion, Eco-training, Teacher training.

\title{
BREVE DISCUSIÓN ACERCA DE LA HISTORIA DE LA INCLUSIÓN EN BRASIL A LA LUZ DE LA COMPLEJIDAD
}

\begin{abstract}
Resumen. La inclusión postula el derecho de todos los sujetos a ser aceptados y respetados frente a las diferencias, en igualdad de condiciones ante la sociedad. La inclusión en la contemporaneidad sigue siendo un elemento perturbador y una fuente de temor en la práctica educativa. No es sólo el profesor el que se siente atraído por la incapacidad de tratar temas con discapacidades en la escuela. Podemos decir que la gran mayoría de los actores educativos comparten esta preocupación. El presente trabajo aborda la historia de la inclusión en Brasil y propone, a partir del paradigma de la Complejidad, un enfoque eco-educativo. Específicamente, este estudio tenía como objetivo hacer un corte teórico-bibliográfico sobre la inclusión y la eco-formación; delinear el fenómeno de la inclusión desde una perspectiva histórica; y discutir la inclusión del ecosistema. Se trata de una investigación cualitativa de carácter web. A partir de la base de datos en línea Scielo, se buscaron estudios que se centraran en el tema de la inclusión desde el paradigma de la Complejidad. Para esta búsqueda, se utilizaron los siguientes términos: la "inclusión", la "formación de profesores" y la "eco-formación". El material recuperado fue sistematizado y, desde la óptica de la teoría de la complejidad, fue posible evidenciarlo. A partir del análisis histórico del proceso de inclusión en Brasil, encontramos que es imperativo que el profesor rompa con las prácticas pedagógicas clásicas a favor del desarrollo de asignaturas únicas y peculiares.
\end{abstract}

Palabras-clave: Inclusión, Ecoformación, Formación docente.

\section{Introdução}

A inclusão postula pelo direito de todos os sujeitos serem aceitos e respeitados diante das diferenças, com igualdade de condições perante a sociedade. A esse respeito, Dorziat (2004) expõe que a inclusão consiste em considerar as diferentes vivências e modos organizacionais de cada grupo, contemplando a subjetividade dos sujeitos, que é constituída por identidades e culturas próprias. Desse modo, segundo Ramos (2011), deve ser garantido a todas as pessoas, independente da sua condição ou característica, acesso às mais diversas oportunidades existentes no meio social que pertencem.

Entretanto, para que haja inclusão é preciso provocar mudanças nos valores sociais e culturais dominantes pois, tais valores seguem impregnados de estereótipos propulsores de exclusão. Acerca disso, Dellani e Moraes (2012, p. 09) afirmam:

a inclusão consiste em adequar os sistemas gerais da sociedade, de tal modo, que sejam eliminados os fatores que excluíam certas pessoas do seu meio e as mantinham afastadas. A eliminação de tais fatores deve ser um processo contínuo e concomitante com o esforço que a sociedade deve empreender no sentido de acolher todas as pessoas independentemente de suas diferenças individuais e de suas origens na diversidade humana. 
Ao pensar a inclusão social nos deparamos com a inclusão escolar, uma vez que a escola tem importante papel na formação do ser social. A inclusão escolar se constitui num movimento mundial que tem como objetivo romper com os paradigmas e com os valores organizacionais, culturais e sociais vigentes (Mantoan, 2003). De acordo com Dellani e Moraes (2012), trata-se de uma educação para todos por meio da qual a diferença é valorizada, buscando a obtenção de conhecimento e preparo para compreender e lidar com as restrições e potencialidades dos sujeitos.

Para entender melhor a importância desse movimento de inclusão voltado para a educação escolar no Brasil, é pertinente discorrer de forma breve sobre o contexto histórico onde ela foi se constituindo.

\section{Um panorama histórico acerca da inclusão escolar no Brasil}

No Brasil a educação escolar começou a ser difundida, com maior proporção, no século XX. Nos períodos do Brasil Colônia (1500 - 1822) e do Brasil Império (1822 1889), a maior parcela da população vivia na zona rural e os trabalhadores - em sua maioria, negros escravizados - não necessitavam de instrução para trabalhar na produção de monocultura dos grandes latifundiários (Kassar, 2011).

De acordo com Januzzi (2012), de modo específico ao que se refere à pessoa com deficiência, é possível apontar que as primeiras instituições educativas brasileiras voltadas para o atendimento especializado desses sujeitos foram criadas no período do Brasil Império. Foram elas: 1) o Imperial Instituto dos Meninos Cegos - Instituto Nacional dos Cegos, posterior, Instituto Benjamim Constant (IBC); 2) e o Instituto dos Surdos-Mudos - Instituto Nacional de Educação de Surdos. A instrução nessas instituições se fundamentava no ideário pedagógico lancasteriano de base francesa.

Segundo Kassar (2011), no início do século XX com o processo de industrialização que se iniciava no Brasil houve um aumento do número de matrículas nas escolas públicas, principalmente da população mais pobre, sendo estes migrantes da zona rural. Em detrimento disso, o autor supracitado expõe que as leis da época revelavam uma preocupação com o estado dessa população, destacando o Art. 826 do Decreto $n^{\circ}$ 5.884 de 1933, na qual sanciona que: "as escolas de débeis físicos se destinam às crianças desnutridas ou em crescimento em atraso as quais convenha regime especial de trabalho escolar, com o fim de reintegrá-las na normalidade física".

Assim, sobre influência Europeia e baseada na ciência médico-pedagógica, no século XX, iniciou-se o uso de teste de Quociente de Inteligência (QI) no Brasil. Desta feita, a partir dos serviços de higiene, com o intuito de organizar salas homogêneas e separar os "normais" dos "anormais" com a criação de classes especiais (Kassar, 2011, Januzzi, 2004, Januzzi, 2012).

Com o fim da segunda Guerra Mundial (1939 - 1945), segundo Januzzi (2004), no Brasil, houve uma exigência mais intensa para educar as pessoas com deficiência buscando torná-las úteis ao mercado e ao meio de produção capitalista. Em decorrência dos efeitos traumáticos do pós-guerra, dentre os quais destacamos os milhares de pessoas mutiladas, em 1948 foi formulada a Declaração dos Direitos Humanos que ressaltava a preocupação pela não discriminação das pessoas com deficiência (Kassar, 2012). Esse documento apontava, dente outros aspectos, a necessidade de se garantir a esses sujeitos o direito a terem diversas experiências em sua vida, nas diversas esferas sociais; direito 
de desenvolver atividades culturais, econômicas e sociais; direito de partilhar ambientes com todos.

Segundo Kassar (2012) essas reivindicações foram incorporadas nas políticas de ações de diversos países no mundo inteiro. No Brasil, em 1961 foi promulgada a primeira Lei de Diretrizes e Bases da Educação Nacional (LDB). Nesta normativa, estava prevista a matrícula dos "excepcionais", mesmo que de forma integradora, tendo em vista que a referida matrícula deveria ocorrer "quando fosse possível" com o intento de normalizar ou integrar esses sujeitos à comunidade.

Segundo Mantoan (2003), o movimento em defesa da inclusão da pessoa com deficiência superou o conceito de integração, e convocou a nova organização do sistema educacional regular e especial, através de uma reformulação das políticas educacionais, visto que a inclusão exige uma mudança radical da sociedade e principalmente do sistema educativo. Deste modo, todos devem ter acesso às salas de aula do ensino regular, sem discriminação e sem isolamento, baseando-se nos princípios inclusivos.

Segundo Baquero (2012), o empoderamento refere-se à aquisição de conteúdo, na qual, os indivíduos ao ganharem conhecimentos adquirem forças para agirem visando à melhoria de suas condições de vida.

Assim, para uma melhor compreensão acerca da inclusão educacional, em seguida abordamos aportes legais que subsidiam o processo inclusivo da pessoa com deficiência.

\section{Breve resgate histórico do movimento da inclusão Escolar da Pessoa com Deficiência no Brasil}

A inclusão educacional é consequência dos movimentos de luta internacionais que tiveram início nos Estados Unidos, por volta dos anos de 1975, visando incluir os grupos minoritários historicamente excluídos. Ao longo dos anos, estes grupos foram conquistando direitos legais, devido às diversas manifestações, principalmente com relação às pessoas com deficiência (Stainbak e Stainbak, 1999). Como resultado desses movimentos, em 1975, foi sancionada a Lei $\mathrm{n}^{\circ}$ 94.142, nos Estados Unidos, dando início ao processo educacional inclusivo naquele país.

No Brasil, em 1988, foi outorgada a Constituição Federal que sinalizou a implementação de uma educação inclusiva ao descrever no inciso III, Art. 208 do Capítulo III, "O dever do Estado com a educação será efetivado mediante a garantia de atendimento especializado aos portadores de deficiência ${ }^{i}$, preferencialmente na rede regular de ensino" (Brasil, 1988).

A Carta Magna do país prevê, no artigo 205, que:

A educação é um direito de todos e dever do Estado e da família e será promovida e incentivada com a colaboração da sociedade, visando ao pleno desenvolvimento da pessoa, seu preparo para o exercício da cidadania e sua qualificação para o trabalho. (Brasil, 1988, Art.205)

O direito de Todos à educação foi reforçado na Conferência Mundial sobre Educação para Todos, que ocorreu em Jomtien, em 1990. Como resultado desta conferência foi redigida a "Declaração Mundial sobre Educação para Todos: satisfação das necessidades básicas de aprendizagem”.

Este documento, em seu Art. $3^{\circ}$, destaca que: 
As necessidades básicas de aprendizagem das pessoas portadoras de deficiências requerem atenção especial. É preciso tomar medidas que garantam a igualdade de acesso à educação aos portadores de todo e qualquer tipo de deficiência, como parte integrante do sistema educativo (p. 04).

Em 1994 com a Conferência Mundial de Educação Especial, em Salamanca, na Espanha, se discutiu sobre uma educação inclusiva para as pessoas com deficiências. Como resultado da conferência foi redigido o documento considerado primordial quando se diz respeito à inclusão educacional, trata-se da Declaração de Salamanca.

Em seu texto, esse documento descreve sobre as escolas inclusivas, considerando que:

Escolas inclusivas devem reconhecer e responder às necessidades diversas de seus alunos, acomodando ambos os estilos e ritmos de aprendizagem e assegurando uma educação de qualidade a todos através de um currículo apropriado, arranjos organizacionais, estratégias de ensino, uso de recurso e parceria com as comunidades (Unesco, 1990, p. 05).

O Brasil, diante desse momento em torno da inclusão, sancionou a Lei de Diretrizes e Bases da Educação Nacional, Lei nº 9.394 de 20 de dezembro de 1996 que, no Art. 58, do capítulo V, rege da seguinte forma "entende-se por educação especial, para os efeitos desta lei, a modalidade de educação escolar, oferecida preferencialmente na rede regular de ensino, para educandos portadores de necessidades especiais" (Brasil, 1996).

Tendo em vista o que fora até então dito, percebe-se que apesar da importância dos aportes legais sobre os direitos dos cidadãos, ainda existem déficits quanto à garantia da inclusão das pessoas com deficiência na escola. O processo inclusivo deve exigir um novo modelo de escola respaldado numa sociedade também inclusiva que garanta a todos os sujeitos, sem distinção, o acesso e a permanência a escola além do seu empoderamento (Dellani e Moraes, 2012; Freire, 2008).

Diante de toda confluência de realidades complexas, desponta a formação do professor, agente fundamental no processo de ensino-aprendizagem e principal condutor do processo de inclusão nos ambientes educacionais. A formação continuada desses atores circunda numa problemática que os (im)possibilita diante da inclusão, já que o metabolismo político do capital os estraçalha. O debate internacional já contemplando nesses escritos e as políticas públicas e legislações nacionais, são insuficientes sem investimentos que proporcionem condições de subsistência e de trabalho. Precisamos evidenciar que sem que haja uma preocupação política-administrativa que se preocupe com aqueles que são os principais agentes do fazer pedagógico na escola, todo esse debate está em risco de falir. Nesse sentido, seria imprescindível lançar luzes acerca da imperiosa necessidade de valorização e de formação em alto nível dos profissionais da educação em geral, e dos professores em específico. É pela via da valorização dos profissionais da educação que se pode produzir uma educação inclusiva de qualidade. Dentre as vias de valorização desses profissionais, destaca-se para esse recorte reflexivo, a formação continuada dos professores. 


\section{A formação dos professores para a Inclusão}

A inclusão na contemporaneidade ainda é um elemento inquietador e de produção de temor na prática educativa. Não é apenas o professor que fica tomado pela inabilidade na lide com sujeitos com deficiência na escola, podemos dizer que a grande maioria dos atores educativos comungam dessa inquietude.

Tomamos por base a nossa experiência na oferta de cursos de formação para professores em nível de extensão universitáriaii. No primeiro momento de apresentação, é quase que uníssono o discurso dos professores na busca do saber-fazer. São rostos apavorados e discursos angustiados diante de um desconhecido, ao tempo que vislumbramos um entusiasmo na busca de produzir novos conhecimentos para aplacar esses sentimentos.

Inferimos quão deficitária pode ser a formação desses profissionais, e quão desvalorizada é a carreira do magistério. O que nos impele aqui a desculpabilizá-los e em tempo, apontar para o descaso político na formação e no reconhecimento desses profissionais. A ausência de investimentos em salários dignos e carga horária condizente a condições físico-intelectuais de possibilitem o exercício de um trabalho de excelência, são fatores anti-inclusivos. Para isso é necessário que façam "investimento em estudos que considerem as políticas, as ações, as dificuldades práticas encontradas pela comunidade escolar em seu trabalho cotidiano" (Briant e Oliver, 2012 p. 145). Precisamos pensar e reivindicar uma formação e o reconhecimento do professor que implique o ato de aprender fazendo, que articule claramente teoria e prática e possibilite a construção de um estilo próprio de ensino, mas que fomente a práxis pedagógica, e a dignidade humana. Caso contrário, diante de uma formação deficitária para a diversidade, a sala de aula pode tornar-se um terreno arenoso para o desenvolvimento humano e educativo dos alunos.

A sala de aula é um espaço em que se encontram sujeitos em diferentes ritmos e capacidades de aprendizagem, com experiências e vivências singulares, com pluralidade cultural e religiosa. Assim, a formação na perspectiva de aprender-fazer dá ao professor instrumentos para decodificar a complexidade dos aprendentes e possibilita a troca de saberes, bem como a produção do desenvolvimento humano (Sanches, 2011).

Para Rodrigues (2008) a formação do professor deve se fundar num percurso que consiste em atender a uma dimensão teórica consistente. Tal que possibilite intervenções pedagógicas fundadas na promoção do desenvolvimento da aprendizagem nos âmbitos específicos de cada caso. Assim, deve promover habilidades que perpassem por distintas escalas como o trabalho comunitário e com famílias. Outra dimensão seria a competência no sentido de ter habilidade para avaliar, planejar e intervir no processo de ensino aprendizagem, para viabilizar a promoção de saberes em um cenário heterogêneo como a sala de aula. Há ainda a necessidade de ocupar, na relação professor-aluno, uma posição empática que nutra a práxis pedagógica. Assim, os recursos que fundam a prática do professor perpassam por habilidades técnicas, científicas e pessoais.

São esses recursos que possibilitam trilhar caminhos desafiadores em direção a inclusão. O processo inclusivo é de responsabilidade de todos, mas o professor é um agente que está nas trincheiras da inclusão. Que na escola assume papel desafiador na busca de construir uma prática pedagógica capaz de atender a cada aluno.

Para executar esta complexa missão, faz-se necessário romper com a formação e as práticas tradicionais para que sejamos capazes de enxergar esses aprendentes como seres complexos e em formação. Isso implica considerar sua condição peculiar frente a 
existência no mundo. Isso implica reavaliar constantemente a práxis, e irromper com o planejamento padrão, uma vez que, as especificidades convocam a um novo saber-fazer. Esse processo exige o desenvolvimento de competências para perceber, no âmbito da escola, os obstáculos que se impõem e sobre eles ter condições e competência de superar.

Necessitamos considerar as questões objetivas que estão no cenário político e que interferem na excelência do desempenho docente, assim como a incoerência entre o legal e as experiências do descumprimento da legalidade constatada nas experiências cotidianas da escola. Há ainda, um imperativo cientifico que se apresenta no intuito de estabelecer uma perspectiva de romper com o clássico, em nome do complexo, para uma outra compreensão da realidade. Assim, nos é exigido refletir sob a perspectiva de um processo inclusivo sustentado nos lastros da ecoformação.

\section{Inclusão e ecoformação: prelúdios de novos olhares}

No início de século XXI novos olhares surgem para compreensão da pessoa com deficiência em nossa sociedade (Nardi, 2007, Alves, 2015, 2016, Pereira Filho, 2019). Ressignificamos valores, pensares, sentires. Abrimo-nos para outras percepções do que é o humano, do que é o conviver, do que é o ser. Para além do "normal e patológico" (Canguilhem, 2009), encontramos o "humano do humano" (Morin, 2002), o "ser em sua inteireza, a inteireza do ser" (Alves, 2016).

O Médico Jorge Canguilhem (2009) já no século XX nos questionava sobre os conceitos de normal e patológico. Assim, solicitava distinguirmos o conceito de saúde, como um conceito não vazio, e sim que possui muitos significados e sentidos. Para tal, o autor parte da premissa de que não é a ausência de normalidade que constitui o anormal. Dizemos isso, uma vez que, a doença se compreende em um estado daquilo que os sujeitos, vivem em referência às normatividades vitais e capacidades inseparáveis dos organismos que produzem suas próprias normas orgânicas. Logo, podemos inferir que saúde e doença podem constituir-se como conceitos dinâmicos, circunstanciados, contíguos à produção de novas normas de acoplamento estrutural entre os organismos e o meio ambiente (Varela, Thompson e Rosch, 2003). Consequentemente, o normal e o patológico, remete-nos ao imperativo de sempre voltar às especificidades e relatividades dos conceitos e contextos.

A normalidade, bem como a inclusão é uma significante para o sujeito. Cada um, quando lhe outorgamos o estado de pertencimento, é capaz de constituir-se dentro da normalidade do/no conviver. Podemos inferir isso pois, ontológica e biologicamente o humano é um ser social, de amorosidade, cooperação e solidariedade (Maturana e Verden-Zoller, 2004). Somos seres de empatia, de criatividade, de conviver. Ou seja, quando, ao sujeito lhe é proporcionado condições de bem-estar no conviver, ser e interagir, consequentemente, incluímos, proporcionamos o pertencimento.

Ao entendermos qual o paradigma dominante do pensar e fazer educação, bem como, política e cultura, compreendemos também as razões pelas quais as pessoas excluem-se umas às outras, bem como, a si próprias em suas imperfeições. Assim, compreender-se é um movimento de redescoberta de novos olhares, novos educares ecoformadores, ecotransformadores. Como afirma Morin (2005 p. 171), cabe a educação a possibilidade :

... de incorporar meios autocríticos e críticos que lhe permitam lutar contra os erros e ilusões, de não sofrer passivamente o imprinting da sua cultura mas, 
ao contrário, de nutrir-se de uma cultura regenerada oriunda da união da cultura humanista e da cultura científica; é capaz de não se deixar sequestrar por ideias mestras possessivas e autoritárias, de desenvolver e afirmar uma consciência ainda hesitante e demasiado frágil, enfim, de desenvolver suas potencialidades ainda não expressas.

Olhar para o humano, olhar para a ciência e olhar para a educação e cultura numa perspectiva complexa, implica perceber a tessitura comum que religa o ser a si mesmo, a sociedade e a natureza realocando-o ao seu real habitat. Promovendo seu habitar-se.

Completa Morin (2007, p.93), nos dizendo que “o modo de pensar clássico, favoreceu a incompreensão de si mesmo, de seus medos, sonhos e dores, de seus autoenganos e suas relações uns com os outros". Maturana e Yanez (2009) expõem que saímos de uma cultura matrística de amorosidade para uma cultura patriarcal, hierárquica do poder (frágil) que trouxe consigo a competição, a auto ilusão, a auto justificação e as cóleras que nos incitam a expulsar-nos de nós mesmos e ao mesmo tempo nos põe em um estado constante de dores, sofrimentos e insanidades. Talvez, o caminho para a serenidade e o empoderamento da vida, esteja na religação, na união, na reconexão. Para tal, a complexidade, a transdisciplinaridade trazem as bases para as práticas ecoformadoras. Reencontrar a tessitura, reencontrar o para além das disciplinas, fronteiras e barreiras.

As práticas ecoformadoras requerem professores com atitudes criativas em sua atuação profissional, tanto na dimensão de uma metodologia que possibilite aos professores o desenvolvimento do trabalho crítico, quanto na articulação de um diálogo entre saberes. Mais que saberes, conteúdos, conhecimentos ou disciplinas, o saber é significante, significado, assimilado e validado quando nos proporciona um estado de religar, de religar-nos, de reinventar o sentido da vida. Um saber que nos empodera enquanto humanos plenos de horizontes criativos e vivos.

Como afirma Moraes (2019, p. 115),

... é preciso vivenciar processos ecoformadores, ou seja, vivenciar experiências educacionais de natureza formativa, enraizadas na dinâmica relacional entre o ser humano, a sociedade e a natureza. É necessário focar as atenções e as reflexões desenvolvidas em direção a estes três níveis de materialidade e que, em realidade, deverão trabalhar as experiências que promovam o autoconhecimento, o respeito e a reverência à vida, a valorização da natureza, a compreensão das relações entre o sujeito e o objeto do conhecimento, lembrando que quem respeita a vida não a destrói, não a mutila e não a condena.

As práticas ecoformadoras propiciam assim, um saber e um conviver mais inclusivo, legitimador, respeitoso e cooperativo, uma vez que, implicam curiosidade, abertura ao novo e ao diferente, humildade e integração (Moraes, 2008). Essas são atitudes que geram o conhecimento da interação entre o ser humano consigo, com o outro e seu habitat. Desta feita, a ecoformação constitui-se na perspectiva do pensar complexo e transdisciplinar. Estes pensamentos legitimam a importância dos conhecimentos de ciências articulados com diversas disciplinas, culturas e outros aspectos que compõem a inteireza humana de modo sistêmico. Aprofundar o trabalho consigo, com o outro e com o mundo diz respeito às ações do professor que contribui para a construção do conhecimento ecoformador. Considerando que a ecoformação favorece a aproximação do sujeito como um ser que pertencente ao mundo e que é produto e produtor de si mesmo. Compete-nos expressar que: 
A ecoformação nos leva a refletir como cidadão enquanto pertencente ao mundo e ao meio ambiente, pois, não somos isolados desse entorno. É um processo educativo de formação para a vida cotidiana que busca as relações do homem com o meio ambiente social e natural: é uma questão de atitude. A ecoformação entende não somente o processo educativo de formação para a vida cotidiana, mas também como um processo que busca as relações do homem com seu meio social e natural (Fachini e Lucia, 2014, p. 3).

Assim sendo, faz-se necessário refletir e perceber que a ecoformação impulsionanos à uma nova consciência, para o despertar de nossa responsabilidade com o outro, conosco e com o mundo. Disso emergem novas atitudes de cuidado, de interdependência com o meio em que vivemos, com as relações e principalmente, com a ideia de cuidar e de si do ser planetário que habita em cada um de nós.

Vivenciarmos o processo ecoformativo em práticas transdisciplinares é ter consciência de nosso enraizamento planetário, biológico, ontológico. Ter consciência de nosso estado como seres ternários, triúnicos: sujeitos parte da sociedade e da natureza. Assim, estar imbricado em práticas docentes baseadas na participação, na solidariedade, no autoconhecimento e na curiosidade. Destarte, necessitamos os processos educativos constituídos de forma multidimensional, multireferenciada, como seres autopoiéticos que somos, para então, romper com as formas passadas de fazer educação.

... a aprendizagem natural intrínseca ao nosso viver/conviver, ela está presente em nossas memórias, em nossos processos autoformativos, heteroformativos ou ecoformativos conscientes ou inconscientes, presentes em nossas experiências de vida, a maioria delas não reconhecidas ou não integradas aos processos formais de educação (Moraes, 2015, p. 9).

Segundo Alves (2016) e Pereira Filho (2019) o percurso ecoformativo que fomenta o processo de inclusão é uma caminhada construída e constituída por superação paradigmática, epistêmica, ontológica e metodológica. É uma jornada de superação de muitas barreiras de uma constante subida de montanhas, de uma dura marcha de resiliência e tenacidade que nos faz ir além. Jornada e caminhada que nos convida a olhar com os olhos da alma, sentir a coragem dos ventos e a força de um rio ao transpor inúmeros obstáculos, ranços de outrora que feriram nossa face com a brutalidade alienante da separação, da dualidade e do abandono social e estatal. Para incluir numa perspectiva ecoformadora, necessitamos mais que bases legais e desenhos universais, precisamos de atitudes e afetos acolhedores, imbuídos do mais profundo bem querer e desejo de partilha emotivamente pleno de saberes e amorosidade.

Para Alves (2016) inclusão é acolhimento, inclusão é pertencimento, é interdependência, é coerência, consciência. Inclusão é abrir-se para um outro modo de fazer educação. Como afirma Moraes (2015, p. 98):

... valoriza os processos de formação integral, ou seja, processos em suas múltiplas dimensões - autoformadora, heteroformadora e ecoformadora. Processos de natureza tripolar e multicausal, como observado por Gaston Pineau (2003), em que cada uma dessas dimensões pode prevalecer em determinados momentos existenciais da vida do aprendiz, das condições e oportunidades recebidas, mas todas elas integram $\mathrm{o}$ movimento transdisciplinar ato pedagógico. Sabemos que a educação tem acima de tudo, como função, despertar a capacidade criadora do indivíduo e fomentar uma ética do conviver. Estimular a construção de uma ética para uma cidadania planetária, para o diálogo intercultural, inter-religioso, e abertura para a 
"inteireza do ser" e na busca do sentido da vida, do estado de pertencimento, de "habitar nossos corpos e o ecos. Assim, estimulamos uma ecoformação.

Destarte, ecoformar é incluir para construir uma nova história, caminhos de uma nova ontogênese humana constituído pela biologia do amar no ato de educar. É celebrar possibilidades ilimitadas de fazer viver a educação. Incluir é acreditar que cada um em sua singularidade é capaz de expressar suas melhores potencialidades.

Ecoformar é a potencialidade de religar saberes e seres a si mesmo e ao todo. Encontrar em cada movimento, em cada diferença, em cada passo, em cada abraço, motivos para acreditar que educação se faz com os melhores valores expressos pelo coração.

Ecoformar é reencontrar-se nó útero do universo, entrar na casa da vida, é como, crianças filhas do universo, em prosa e verso, abrirmo-nos para curiosidade epistemológica de novos aprenderes. Não é sobre qualquer aprender, é o aprender com a mente, corpo, alma, emoção, intuição e espírito. Uma aprendizagem transdisciplinar, transgressora, transformadora, e, portanto, singular. Uma aprendizagem legitimadora da autoria de pensamento, da inteireza da vida e do viver (Alves, 2016; 2015).

\section{Referências}

Alves, M. D. F. (2016). Práticas de aprendizagem integradoras e inclusivas: Autoconhecimento e motivação. Rio de Janeiro: WAK.

Alves, M. D. F. (2015). De professor a educador - contribuições da psicopedagogia: ressignificar os valores e despertar a autoria. $3^{\mathrm{a}}$ ed. Rio de Janeiro: WAK Editora.

Alves, M. D. F. (2015). Reflexões sobre aprendizagem: De Piaget a Maturana. Revista e-Curriculum, 13(4), 838-862.

Baquero, R. V. (2012). Empoderamento: Instrumento de emancipação social? Revista Debates, 6(1), 173-187.

Brasil (1988). Constituição da República Federativa do Brasil de 1988 (1988, 5 de outubro). Brasília: Senado Federal.

Brasil (2015). Decreto Lei ${ }^{\circ}$ 13.146, de 6 de julho de 2015. Institui a Lei Brasileira de Inclusão da pessoa com deficiência. Recuperado em 19 de julho de 2019, de http://www.planalto.gov.br/ccivil_03/_Ato20152018/2015/Lei/L13146.htm.

Brasil (2018) Lei de Diretrizes e Bases da Educação Nacional: Lei no 9.394, de 20 de dezembro de 1996, que estabelece as diretrizes e bases da educação nacional. - 5 . ed. - Brasília: Câmara dos Deputados, Coordenação, 5 Edições Câmara, 2010. Recuperado em 21 de junho de 2019, de http://www.famasul.edu.br/2015/arquivos_pdf/106.pdf.

Brasil (2010). Ministério da Educação. Marcos Político-Legais da Educação Especial na Perspectiva da Educação Inclusiva - Brasília: Secretaria de Educação Especial, 2010. Recuperado em 16 de junho de 2019, de http://portal.mec.gov.br/index.php?option=com_docman\&view=download\&alia $\mathrm{s}=6726$-marcos-politicos-legais\&Itemid=30192.

Dellani, M. P. e Moraes, D. N. (2012). Inclusão: caminhos, encontros e descobertas. Revista de Educação do IDEAU, 7(15), 2-13, jan.;jun. Recuperado em 20 de junho 
de 2019, de http://docplayer.com.br/7446537-Inclusao-caminhos-encontros-edescobertas.html.

Dorziat, A. (2004). Educação de surdos no ensino regular: inclusão ou segregação? Revista de Educação Especial, 2(24), 77-85, 2004. Recuperado em 18 de julho de 2019, de https://periodicos.ufsm.br/educacaoespecial/article/view/4921/2955.

Jannuzzi, G. S. M. A. (2012). Educação do deficiente no Brasil: dos primórdios ao início do século XXI. $3^{\text {a }}$ ed. Campinas: Autores Associados.

Jannuzzi, G. S. M. A. (2004). Algumas concepções de educação do deficiente. Rev. Bras. Cienc. Esporte, 25(3), 09-25, maio. Recuperado em 17 de julho de 2019, de http://revista.cbce.org.br/index.php/RBCE/article/view/235/237.

Kassar, M. C. M. (2011). Educação especial na perspectiva da educação inclusiva: desafios da implantação de uma política nacional. Educar em Revista, 41, 6179jul./set. Recuperado em 20 de junho de 2019, de http://www.scielo.br/pdf/er/n41/05.pdf.

Kassar, M. C. M. (2011). Educação especial no Brasil: desigualdades e desafios do reconhecimento da diversidade. Educ. Soc., 33(120), Campinas, 833-849, jul./set. Recuperado em 17 de junho de 2019, de http://www.scielo.br/pdf/es/v33n120/10.pdf.

Mantoan, M. T. E. (2003). Inclusão escolar: O que é? Por quê? Como fazer? São Paulo: Moderna.

Maturana, H. e Verden-Zoller, G. (2004). Amar e brincar: fundamentos esquecidos do humano. São Paulo: Palas Athena.

Maturana, H, e Yanez, X. D. (2009). Habitar humano em seis ensaios de biologia-cultural. São Paulo: Palas Athena.

Moraes, M. C. (2015). Transdisciplinaridade, criatividade e educação: Fundamentos ontológicos e epistemológicos. Campinas: Papirus.

Moraes, M. C. (2019). Saberes para uma Cidadania Planetária: homenagem a Edgar Morin. Rio de Janeiro: Wak Editora.

Morin, E. (1997). Introdução ao pensamento complexo. Lisboa: Instituto Piaget.

Morin, E. (2007). Educação e Complexidade: Os sete saberes e outros ensaios. São Paulo: Cortez.

Nardi, R. G. (2007). Ressignificando a educação especial a partir da complexidade e do pensamento eco-sistêmico. Tese de Doutorado. São Paulo: Programa de Pósgraduação em Educação. São Paul: PUC/SP.

Ramos, L. D. (2011). O direito constitucional à inclusão do deficiente auditivo na rede regular de ensino: um estudo de sua eficácia no município de campos novos. Revista da ESMESC, 18(24), 391-420.

Rodrigues, D. (2008). Desenvolver a educação inclusiva: dimensões do desenvolvimento profissional. Inclusão: Revista da Educação Especial, 4(2), 7-16.

Saviani, D. (1995). Pedagogia Histórico-crítica: primeiras aproximações. 5. ed. Campinas: Autores Associados.

Sanches, I. (2011). Do aprender para fazer ao aprender fazendo: as práticas de educação inclusiva na escola. Revista Lusófona de Educação, 19, 135-156. 
Stainback, S. e Stainback, W. (1999). Inclusão: um guia para educadores. Porto Alegre: Artes Médicas.

Unesco (1990). Declaração Mundial sobre Educação para Todos: satisfação das necessidades básicas de aprendizagem. Jomtien. Recuperado em 6 de julho de 2019, de http://unesdoc.unesco.org/images/0008/000862/086291por.pdf.

Varela, F., Thompson, E. e Rosch, E. (2003). A mente incorporada: ciências cognitivas e experiência humana. Porto Alegre: Artmed.

\footnotetext{
i Esse termo 'portador de deficiência' caiu em desuso com a Portaria SEDH no 2.344, de 3 de novembro de 2010, que em seu Artigo $2^{\circ}$, inciso I, institui que, "Onde se lê "Pessoas Portadoras de Deficiência", leia-se "Pessoas com Deficiência" (Brasil, 2010), visto que essa Portaria atualiza o Regime Interno do Conselho Nacional dos Direitos da Pessoa com Deficiência (CONADE).

ii $\mathrm{O}$ curso de práticas de aprendizagem integradoras e inovadoras é ofertado a nível de extensão na UFAL. É destinado aos professores da educação básica de escolas públicas e privadas e objetiva contribuir para a polinização de metodologias inovadoras, integradoras e inclusivas na formação docente.
}

Data da recepção: $15 / 09 / 2019$

Data da revisão: $21 / 10 / 2019$

Data do aceite: 23/10/2019 